\title{
A Generalized Analysis of Energy Saving Strategies Through Experiment for CNC Milling Machine Tools
}

Chunhua Feng ( $\nabla$ science_chf@126.com )

University of Shanghai for Science and Technology

Xiang Chen

University of Shanghai for Science and Technology

Jingyang Zhang

University of Shanghai for Science and Technology

Yugui Huang

University of Shanghai for Science and Technology

\section{Research Article}

Keywords: energy predict model, energy-saving strategy, CNC milling process, tool path

Posted Date: April 12th, 2021

DOI: https://doi.org/10.21203/rs.3.rs-380607/v1

License: (9) This work is licensed under a Creative Commons Attribution 4.0 International License. Read Full License

Version of Record: A version of this preprint was published at The International Journal of Advanced Manufacturing Technology on July 31st, 2021. See the published version at https://doi.org/10.1007/s00170-021-07787-9. 


\title{
A generalized analysis of energy saving strategies through experiment for CNC milling machine tools
}

\author{
Chunhua Feng ${ }^{1}$, Xiang Chen ${ }^{1}$, Jingyang Zhang ${ }^{1}$, Yugui Huang ${ }^{1}$ \\ 1. School of Mechanical Engineering, University of Shanghai for Science and Technology, Shanghai 200093 \\ The corresponding author: Chunhua Feng, E-mail: science_chf@126.com
}

\begin{abstract}
This paper proposes the elaboration model of energy requirement prediction taking into account the power of standby, spindle rotation in non-load, feeding and rapid movement in X, Y, Z+ and Z- axially, and specific energy consumption (SEC) in the $\mathrm{X}$ and $\mathrm{Y}$ cutting directions respectively, which could not be considered completely in other models. Each part energy of specific machine tools could be obtained through little experiments for identifying the relationship between energy and tool path with cutting parameters. The method is validated by 27 trial cutting experiment in $\mathrm{X}$ and $\mathrm{Y}$ cutting directions in VMC850E machine, the results show that the SEC in the $\mathrm{X}$ and $\mathrm{Y}$ cutting directions are exactly different. Moreover, it is found that spindle power should be piecewise linear representation according to spindle speed characteristic, due to the correlation coefficient of power model only has $25.45 \%$ without segmented. Additionally, the correlation coefficient of improved SEC model could reach to more than $99.98 \%$ in each segment. The contribution of this paper is mainly the elaboration energy consumption model considering the cutting direction, which is an efficient approach for predicting energy consumption through tool path to achieve sustainable production in manufacturing sectors.
\end{abstract}

Keywords: energy predict model; energy-saving strategy; CNC milling process; tool path

\section{Introduction}

The manufacturing industry consumes a lot of energy and consequently has to adopt energy-saving techniques such as optimization of workshop scheduling, machine tools structure, machining process, and process path [1]. The effective implementation of manifold measures for increasing energy efficiency has had a positive effect on reducing electricity consumption from workshop to machining process. Additionally, the improvement of machining process play more important role on the condition of fixed machine tools, especially the cutting parameters, tool path, process route, and so on [2]. Computer numerical control $(\mathrm{CNC})$ machining play a significant role in manufacturing activities with the advantage of highly automated control system. For CNC equipment, it executes the NC notes step by step through tool activities based on workpiece geometry. Therefore, it is indispensable to establish the elaboration energy consumption model for $\mathrm{CNC}$ machining considering $\mathrm{NC}$ nodes implementation activities to evaluate energy efficiency of specific part machining. Due to the complexity of operating principle and activities in each axis direction for different kinds of $\mathrm{CNC}$ machine, it can be challenging to establish elaboration energy requirements model under complexity of cutting parameters and tool path.

The current research on machining energy consumption focus on material remove process, auxiliary system, and whole energy calculation. The methods could be classified into general methods and intelligent methods according to whether or not using big data information and artificial intelligence approach.

The general methods mainly concentrate on establishment of energy efficiency model for excavating the interrelation of unit energy consumption and machining parameters. A generalized representation of most existing energy models is from Gutowski et al. [3] using material removal rate (MRR) as the norm when modeling energy usage in machining, which is widely adopted and improved by many researchers. Following observation of MRR and specific energy consumption, Diaz et al. [4] validated the MRR's effect on energy consumption through experiment in a 3-axis machining center. Similarly, Kara and Li [5] verified the SEC model of Gutowski et al. [3] to characterize the correlation with MRR through five turning machines and three milling machines. Except MRR, it is noted that the spindle speed also has an important effect on the total cutting energy. Thus, Li et al. [6] proposed the 
improved SEC model for expressing correlation with $n$ and MRR proved through orthogonal experiment. Unlike above models considering MRR and $n$ as an aggregate function of cutting process, Newman et al. [7] partially considered the contribution of individual process parameters (depth of cut) to cutting power for selecting energy efficiency process planning. Meanwhile, Balogun and Mativenga [8] researched the influence of toolpaths (including tool life) on energy requirements, and first proposed the speed power segmented characteristic based on speed. However, the MRR-based methods only take into account partly toolpaths influence, and little experiments are carried out focusing on cutting directions differences for turning or milling machining.

Additionally, in practical energy consumption calculation, the entire energy consumption requirements for machining a workpiece should also be obtained for understanding machine tools' characteristic. The power mainly takes into account of standby, feed axis movement, air cut, and cutting process occupying the main position. Diaz et al. [4] calculated the energy consumption through divided power into cutting and air cutting states. Similarly, Mori et al. [9] and Balogun et al. [10] identified the power into constant power, cutting, and air cutting to calculate energy requirements and carbon emission with corresponding running time. He et al. [11] proposed the practical calculation method of NC machining through decomposing subsystems of CNC machines. For better identifying the energy state of machines, Behrendt et al. [12] developed the monitoring system for machine tools, which research the energy constitutes all of the nine machine tools. From the results, we found that spindle power follow a linear relationship with spindle speed for turning machine. Altıntaş et al. [13] (2016) developed a different spindle power model in 5axis vertical machining center founding that the power load of the spindle changes with the speed. Similarly, Moradnazhad and Unver [14] analyzed the energy characteristics of turn-mill machining in feed movement in X, Y, $\mathrm{Z}+$ and $\mathrm{Z}$ - as well as main spindle and sub-spindle. That means that the relationship trend between the spindle power of different kinds of machine tools and speed are not always a linear proportional constants in each speed space. Thus, the air cut power should be modeled accurately based on spindle running characteristic for specific machine. Hu et al. [15] calculated energy considering cutting and non-cutting state for optimizing the cutting parameters according to theoretical power model and time relationship with process parameters. The major existing models are collected as shown in Table 1.

With the development of Internet of Things technology, intelligent methods are being studied in recently years to monitor and manage energy consumption in machining workshop. Shin et al. [16] established an online optimization model adopting dynamic composition approach and divide-and-conquer technique based on component. Chen et al. [17] proposed the framework of Internet of Things to monitor and management energy contributing to identify the strategies of reducing energy. The deep learning algorithms are used to establish a generic energy prediction model in [18] for identifying energy consumption characteristics among different machine tools under the condition of big machinery data. Xu et al. [19] proposed a novel intelligent reasoning system to assess energy consumption and optimize cutting parameters through black-box theory. Intelligent methods for energy consumption prediction are still under development, which still have many problems to be solved such as how to let users understand the specific meaning of energy consumption in black-box and how to calculate the energy consumption for machined component. While intelligent design methods are mainly deep learning, neural networks, etc. The key is the accuracy of a large amount of data processing, which is a black box structure. It is effective in the management of the energy consumption of the workshop and the machine tools, but it is difficult to understand the energy construction for a single component. From the above analysis, we observe the existing energy models have not studied the influence of spindle power characteristic under non-load on all cutting power model. 
Table 1 A summary of major energy consumption models

\begin{tabular}{|c|c|}
\hline Literature & Model \\
\hline Gutowski et al. 2006 & $\begin{array}{l}E=\left(P_{0}+K \cdot M R R\right) \cdot t \\
P_{0} \text { represents the portion of total energy consumed at a constant rate, while } K \cdot M R R \text { represents energy required for } \\
\text { material removal proportional to the } M R R .\end{array}$ \\
\hline $\begin{array}{l}\text { Diaz et al., 2011; Kara and } \\
\text { Li, } 2011\end{array}$ & $\mathrm{E}_{\mathrm{cut}}=\mathrm{SEC} \cdot V_{c u t}=\left(C_{0}+\frac{C_{1}}{M R R}\right) \cdot V_{c u t}$ \\
\hline & $\mathrm{C}_{0}$ and $\mathrm{C}_{1}$ are the coefficients related to the specific machine tool. \\
\hline Li et al., 2013 & $\begin{array}{l}\mathrm{E}_{\text {cut }}=\mathrm{SEC} \cdot V_{c u t}=\left(k_{0}+k_{1} \frac{n}{M R R}+k_{2} \frac{1}{M R R}\right) \cdot V_{c u t} \\
n \text { is the spindle speed; } k_{0}, k_{1} \text {, and } k_{2} \text { are the coefficients related to the machine tool. }\end{array}$ \\
\hline Diaz et al. 2011 & $\begin{array}{l}\mathrm{E}=\left(P_{\text {cut }}+P_{\text {air }}\right) \cdot t \\
P_{\text {cut }} \text { represents the power of cutting process, } P_{\text {air }} \text { represents the power of air process. }\end{array}$ \\
\hline Mori et al. 2011 & $\begin{array}{l}E=P_{1} \times\left(T_{1}+T_{2}\right)+P_{2} \times T_{2}+P_{3} \times T_{3} \\
P_{1} \text { is the constant power during the machine operation, } T_{1} \text { is the cycle time during non-cutting stage, } T_{2} \text { is the cycle } \\
\text { time during cutting state, } P_{2} \text { is the power for cutting by the spindle and servo motor, } P_{3} \text { is the power to position the } \\
\text { work and to accelerate/decelerate the spindle to the specified speed, } T_{3} \text { is the time for spindle rotation. }\end{array}$ \\
\hline He et al. 2012 & $\mathrm{E}=\int_{t_{s p}} P_{s p} d t+\int_{t_{c u t}} P_{c u t} d t+\sum_{i=1}^{m} \int_{t_{f}} P_{i} d t+P_{\text {cool }} t_{c o o l}+P_{t c} t_{t c}+\left(P_{\text {servo }}+P_{\text {fan }}\right) t$ \\
\hline & $\begin{array}{l}\mathrm{P}_{\mathrm{sp}} \text { is the power of spindle with corresponding time } \mathrm{t}_{\mathrm{sp}}, \mathrm{P}_{\text {cut }} \text { is the cutting power with time } \mathrm{t}_{\text {cut }}, i \text { is the } i \text { th axis, } \mathrm{m} \text { is } \\
\text { the number of axis, } \mathrm{P}_{\mathrm{i}} \text { is the feed power for } i \text { th axis, } \mathrm{P}_{\text {cool }} \text { is the power of cooling system with time } \mathrm{t}_{\text {tool }}, \mathrm{P}_{\mathrm{tc}} \text { is the } \\
\text { power of tool-change with time } \mathrm{t}_{\mathrm{tc}}, \mathrm{P}_{\text {serve }} \text { and } \mathrm{P}_{\text {fan }} \text { are the power of servos systems and fan motors separately with } \\
\text { time } t \text {. }\end{array}$ \\
\hline $\begin{array}{l}\text { Balogun and Mativenga, } \\
2013\end{array}$ & $\mathrm{E}=E_{b}+E_{r}+P_{t c} \cdot t_{t c}\left[I N T\left(\frac{t_{2}}{T}\right)+1\right]+P_{\text {air }} \cdot t_{\text {air }}+\left(P_{s}+P_{c o o l}+k \cdot M R R\right) \cdot t_{c}$ \\
\hline & $\begin{array}{l}E_{b} \text { is the basic energy, } E_{r} \text { is the ready state energy, } P_{t c} \text { is the tool change power with time } t_{t c}, T \text { is the tool life, } P_{a i r} \\
\text { is the air cutting power with the time } t_{\text {air }}, P_{s} \text { and } P_{c o o l} \text { are the power of spindle and coolant system respectively, } t_{c} \\
\text { is the cutting time, } k \cdot M R R \text { represents energy required for material removal proportional to the MRR. }\end{array}$ \\
\hline
\end{tabular}

Although the existing energy models have improved prediction precision, there are still some problem requiring in-depth study.

(1) Most existing models assumed the cutting power is the same in $\mathrm{X}$ and $\mathrm{Y}$ cutting direction without considering cutting direction, while we found that it is different in our experiment. Additionally, we also found that the spindle power is not always linear proportional increasing relation because of the different principle of constant torque speed regulation and constant power speed regulation. The different trend of spindle power directly affects the accuracy of cutting power prediction due to the spindle support most of the load during the material cutting process. This issue is also be found in some research review $[12,13]$, while did not conduct in-depth research. Therefore, it is necessary to improve the spindle power model.

(2) Additionally, the existing SEC model assumed that the energy required to remove the same material is also the uniform in all cutting directions (X, Y, Z and other axis for 5-axis machine), while practically this assumption is defective due to different axis undertake different loads depending on the direction of motion. This phenomenon has been verified in our experiment and some research literatures [13, 20].

(3) One NC code could describe a whole machining process, and hence, the energy consumption could be 
predicted based on correlation coefficient of selected machine. Some model such as SEC could not directly calculate energy consumption of each activities during the executive process of NC nodes [21]. Thus, the energy prediction for the spindle axis, feed axis, and cutting axis should be established based on the tool paths from NC codes.

Based on the above analysis, the aim of this paper is to study energy consumption model for 3-axis CNC machining process through experiment test. The proposed energy model is based on selected CNC machines, individual process parameter, cutting directions in 3-axis machining. We also find that spindle power is not always be linear proportional increasing trend with spindle speed due to the different speed control methods (constant torque speed regulation and constant power speed regulation). That directly affects the accuracy of energy consumption calculation in the air cutting process. Especially, specific energy consumption model also be affected when reaching the rated power of the spindle. Therefore, it is necessary for improving the existing energy model through piecewise way according to spindle speed. Another contribution of this paper is to develop energy model for CNC milling considering each activity of tool path and machine movement.

The rest of this paper is arranged as follows. The improved energy model for CNC machine is presented in Section 2. Section 3 gives the experiment design and results analysis. Finally, the conclusion and future work are drawn in Section 4.

\section{The elaboration model analysis of energy consumption}

Energy consumed of running an NC block for machining component on CNC equipment could be divided into two parts---consume energy at a constant rate, and consume energy at a variable rate.

$$
E_{N C-b l o c k}=E_{\text {constant }}+E_{\text {variable }}
$$

where $E_{N C \text {-block }}$ is the energy consumed by a component, $E_{\text {constant }}$ is the consume energy at a constant rate (like standby, coolant fluid, and tool change) without relation with cutting parameters, $E_{\text {variable }}$ is the consume energy at a variable rate decided by cutting parameters, tool path, and movement directions.

$$
E_{N C-b l o c k}=E_{\text {standby }}+E_{\text {coolant }}+E_{\text {tool_change }}+E_{\text {rapid }}+E_{\text {spindle }}+E_{\text {feed }}+E_{\text {cut }}
$$

Since the energy required in different components machining operation, the total energy consumption is calculated through identifying energy need of each activity in its NC program. Due to NC codes reflect the used manufacturing method including energy requirements of all activities, it is better method to calculate energy demand based on $\mathrm{G}$ code. Meanwhile, each activity machining time can be also calculated according to cutting parameters and tool information. Additionally, the power of each activity is obtained by little experiment on CNC equipment. It is key step to establish power model of specific $\mathrm{CNC}$ machine for predicting energy consumption, which is be expressed as

$$
P=P_{\text {standby }}+P_{\text {coolant }}+P_{\text {tool_change }}+P_{\text {rapid }}+P_{\text {feed }}+P_{\text {spindle }}+P_{\text {cut }}
$$

where $P_{\text {standby }}$ constitutes the controller, lights, etc. $P_{\text {coolant }}$ is the coolant fluid power depending on the state of the machine. The tool generally need rapid feed to the workpiece coordinate point, which also need power ignored in other power model. $P_{\text {tool_change }}$ is the power of changing tool. $P_{\text {rapid }}$ is the power of the rapid movement of axis. $P_{\text {feed }}$ is the power of feed in different axis $(\mathrm{X}, \mathrm{Y}$ and $\mathrm{Z})$ used in air feed movement between two points. $P_{\text {spindle }}$ is the power of spindle rotation related to spindle speed. $P_{\text {cut }}$ is power drawn from removing material. Considering the corresponding time of each acidity, the energy of one NC-block is expressed as

$$
E_{N C \text {-block }}=P_{\text {standby }} \cdot t_{\text {standby }}+P_{\text {coolant }} \cdot t_{\text {coolant }}+P_{\text {tool_change }} \cdot t_{\text {tool_change }}+P_{\text {rapid }} \cdot t_{\text {rapid }}+P_{\text {spindle }} \cdot t_{\text {spindle }}+P_{\text {feed }} \cdot t_{\text {feed }}+P_{\text {cut }} \cdot t_{\text {cut }}
$$

The feed power includes rapid power and air feed power according to movement rate. The rapid feed rate is constant decided by machine tool design structure, and hence, it is constant obtained by experiment on different axis expressed as $\mathrm{P}_{\text {rapid }}^{x}, \mathrm{P}_{\text {rapid }}^{y}, \mathrm{P}_{\text {rapid }}^{z}$. The air feed power is different on different axis affected by feed rate, which is the 
proportional to the feed rate. They are expressed as

$$
\begin{gathered}
\mathrm{P}_{\text {feed }}^{x}=k_{x_{-} \text {feed }}^{1}+k_{x_{f} \text { feed }}^{2} \cdot f \\
\mathrm{P}_{\text {feed }}^{y}=k_{y_{-} \text {feed }}^{1}+k_{y_{f} \text { feed }}^{2} \cdot f \\
\mathrm{P}_{\text {feed }}^{z+}=k_{z+_{\text {feed }}}^{1}+k_{z+_{\text {feed }}}^{2} \cdot f \\
\mathrm{P}_{\text {feed }}^{z-}=k_{z_{\text {feed }}}^{1}+k_{z_{\text {feed }}}^{2} \cdot f
\end{gathered}
$$

Where $k_{x_{-} \text {feed }}^{1}$ and $k_{x_{-} \text {feed }}^{2}$ is the coefficient of $x$ axis feed movement, and $f$ is the feed rate. The feed distance in different axis is different, and hence, it assists to calculate accurately energy consumption due to different axis movement with different mass.

Non-cutting state includes standby, spindle and axis movement activity. From our experiment observations, it can be drawn that the energy need of each axis movement is the linear relation with feed rate. Similarly, the energy need of spindle rotation is the linear or quadratic linear relation with spindle speed in different speed space. The spindle motor has stepless speed regulation and frequency conversion speed regulation, so the linear relationship between direct power and motor speed is sometimes invalid. For the spindle motor that usually adopts frequency conversion speed regulation, when it runs above the reference frequency, the loss of the motor itself will remain unchanged, and even slightly decrease with the increase of the speed. This is the same as the spindle rotation power in the linear equation. The assumption of linear increase is contradictory. It is found through experiments that it can generally be divided into three or four sections. According to the structure of different machine tools, the relationship between spindle speed and power can even be divided into four or five sections. This situation will affect the prediction of the overall energy consumption of the processed parts, as follows:

$$
\left.P_{\text {spindle }}=\begin{array}{cc}
k_{s 0}^{1}+k_{s 0}^{2} \cdot n & 0<n<n_{1} \\
k_{s 1}^{1}+k_{s 1}^{2} \cdot n & n_{1}<n<n_{2} \\
k_{s 2}^{1}+k_{s 2}^{2} \cdot n & n_{2}<n<n_{3} \\
k_{s 3}^{1}+k_{s 3}^{2} \cdot n & n_{3}<n<n_{4}
\end{array}\right\}
$$

Where $n$ is the spindle speed, $k_{S}^{1}$ and $k_{S}^{2}$ is the coefficient on corresponding $n$ interval.

Specific energy consumption for cutting process is the proportional to MRR and $n$, while MRR is calculated through integrating cutting parameters of feed rate, width of cut and depth of cut. The correlated coefficient is determined by specific machine as well as cutting direction. Specific energy consumption of cutting operation is expressed as

$$
\left.\begin{array}{l}
S E C_{x}=k_{0}^{x}+k_{1}^{x} \cdot \frac{n}{M R R}+\frac{k_{2}^{x}}{M R R} \\
S E C_{y}=k_{0}^{y}+k_{1}^{y} \cdot \frac{n}{M R R}+\frac{k_{2}^{y}}{M R R} \\
S E C_{z}=k_{0}^{z}+k_{1}^{z} \cdot \frac{n}{M R R}+\frac{k_{2}^{z}}{M R R}
\end{array}\right\}
$$

$S E C_{x}, S E C_{y}$ and $S E C_{z}$ is a function of MRR and $n$ in corresponding axial cutting direction. Where $k_{0}, k_{1}$, and $k_{2}$ are the coefficients related to the machine tool. $S E C_{x}$ and $S E C_{y}$ are the specific energy consumption in $\mathrm{X}$ axis cutting and $\mathrm{Y}$ axis direction separately during the milling machining. $S E C_{z}$ represents the drilling machining in $\mathrm{Z}$ axis direction. The energy required in one cutting direction (like $x$ axis) is calculated as

$$
E_{\text {cut } x}=S E C_{x} \cdot V_{\text {cut }}
$$

Similarly, the energy required of other axis could be calculated through the same equation. Using of our proposed model, the users just determine the customization constants for their machine under current state. Meanwhile, each coefficient is determined by little experiments for specific machine without requiring more sensors and handbooks.

$$
\begin{gathered}
\mathrm{E}=P_{\text {standby }} \cdot t_{\text {standby }}+P_{\text {coolant }} \cdot t_{\text {coolant }}+P_{\text {rapid }} \cdot t_{\text {rapid }}+\sum\left(P_{\text {tool_change }} \cdot t_{\text {tool_change }}\right)+P_{\text {spindle }} t_{\text {spindle }}+\Sigma x, y, z\left(P_{\text {feed }} \cdot t_{\text {feed }}\right)+ \\
\Sigma x, y, z\left(S E C_{x} \cdot V_{\text {cut }}\right)
\end{gathered}
$$




\section{Experimental method and results}

\subsection{Experiments set-up}

The power of each part is obtained in a 3-axis VMC850E milling center with $7.5 \mathrm{KW}$ rated power, $8000 \mathrm{rpm}$ maximum spindle speed and $380 \mathrm{~V}$ voltage. The other information and equipment set-up are shown in Table 2 and Fig.1. The aluminum alloy material is used as the machined workpiece for experimental trials. Additionally, the machining is proceeded in dry conditions using tool with $8 \mathrm{~mm}$ diameter.

\begin{tabular}{ll}
\multicolumn{2}{l}{ Table 2 Technical specifications of vertical machining center used in the study } \\
\hline Shenyang VMC850E & Parameters \\
\hline Power supply & $380(1 \pm 10 \%)$ V $50 \mathrm{HZ}$ \\
Table travel (mm) XYZ & $850 / 500 / 540$ \\
Spindle speed & $0-8000 \mathrm{RPM}$ \\
Maximum weight on table & $450 \mathrm{Kg}$ \\
Spindle motor power & $7.5 \mathrm{KW}$ \\
Feed motor power (X、Y and Z ) & $3 \mathrm{KW}$ \\
Rapid feed rate (X and Y) & $24 \mathrm{~m} / \mathrm{min}$ \\
Rapid feed rate (Z) & $15 \mathrm{~m} / \mathrm{min}$ \\
Tool diameter (D) & $8 \mathrm{~mm}$ \\
No. of teeth (N) & 3 \\
\hline
\end{tabular}

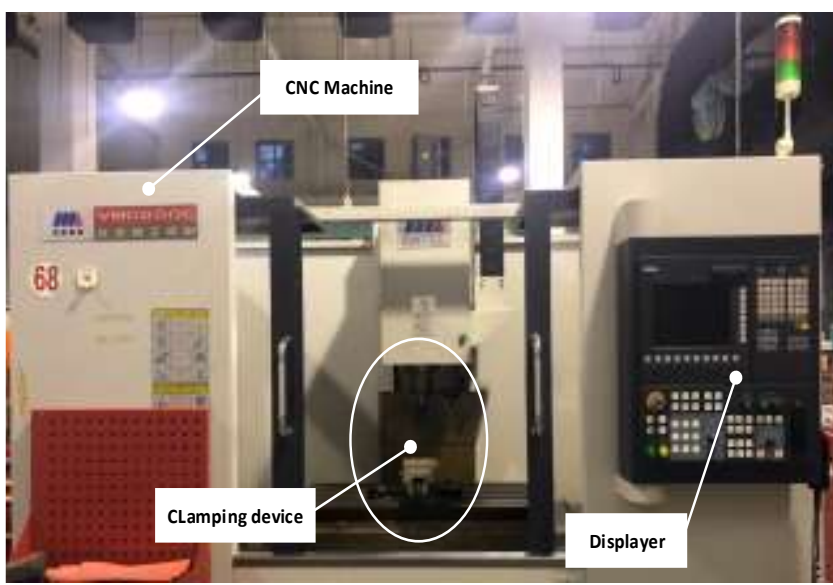

(a)

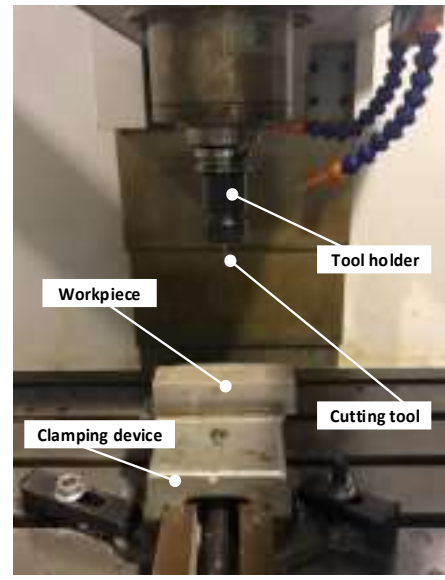

(b)

Fig.1. (a) VMC850E machine (b) Machined workpiece and cutting tool

The power was monitored by a WB9128-1 three-phase power sensor, which comprised of AC voltage wiring input and $\mathrm{AC}$ current through the heart input mounted on both sides of the input voltage terminal of the machine tool. The connection method is shown in the Fig.2. The power sensor adopts a three-phase three-wire wiring method. The entire data acquisition module includes a signal acquisition block, a signal conditioning block, a computer display block and a power supply block. The signal acquisition module with NI-9201 collects the corresponding physical signal, the sensor collects the physical signal, and converts it into an analog or digital signal. Then it transmits the signal to the signal conditioning module, which is processed by the signal conditioning block and directly transmitted to the acquisition card, and then converted from the acquisition card to the USB interface signal transmitted to the computer. Sampling rate of measuring was $200 \mathrm{~Hz}$ (the VMC850E is $50 \mathrm{~Hz}$ ). 


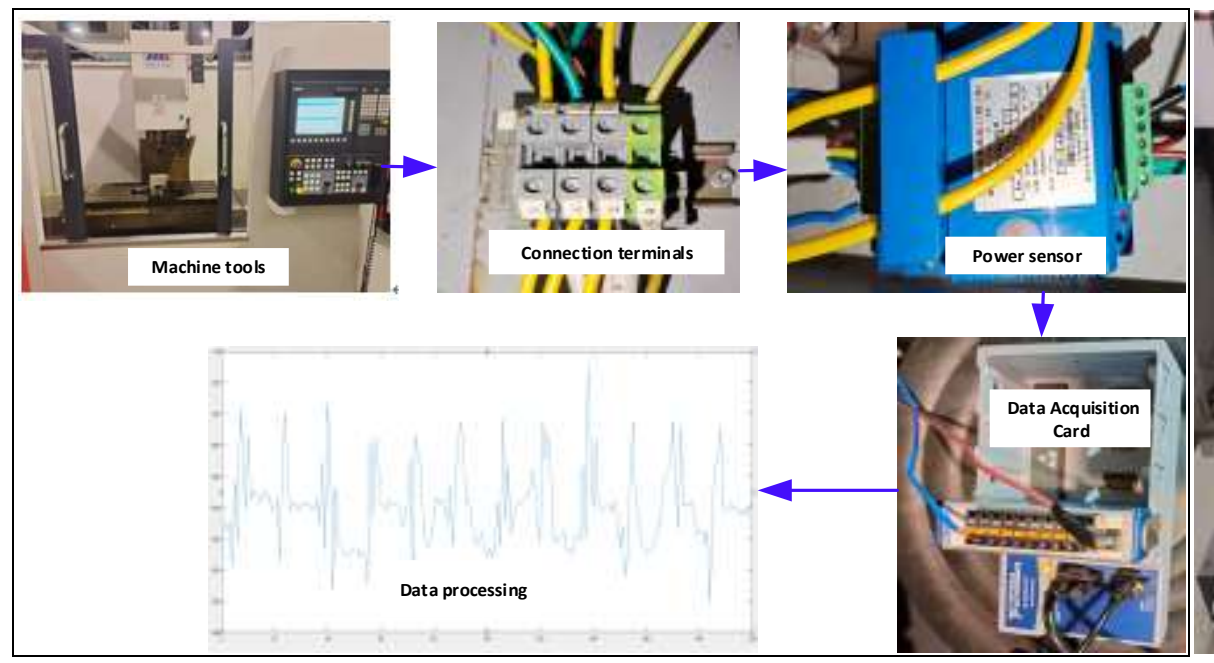

(a)

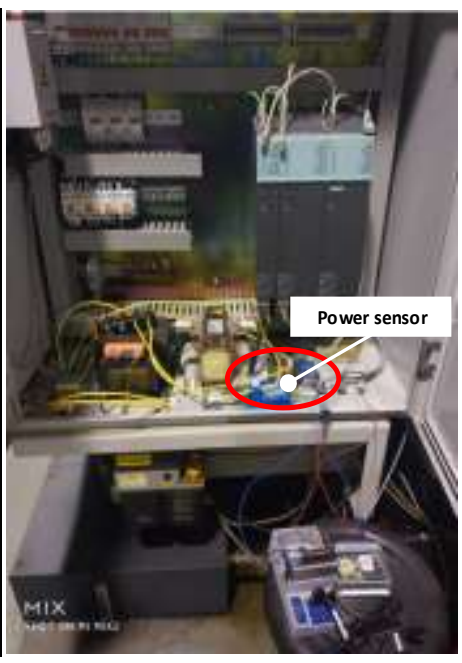

(b)

Fig.2 (a) A diagram for the power data acquisition (b) Connection diagram

\subsection{Design of experiments}

The standby power is obtained through 20 times measurement when machine tools is opened with display screen. The final numerical value is the average power of 20 times. The rapid power in $\mathrm{X}, \mathrm{Y}$ and $\mathrm{Z}$ axis are obtained through G00 rode in corresponding axis movement. Meanwhile, the spindle power at different speed is measured from 500rpm to $5100 \mathrm{rpm}$. The feed power for X, Y, Z- and Z+ axis are obtained in different feed rates. Orthogonal experiment is designed by 27 trial in $\mathrm{X}$ direction and $\mathrm{Y}$ direction cutting process separately for identifying their differences for energy consumption. Toolpath strategies are shown in Fig.3.

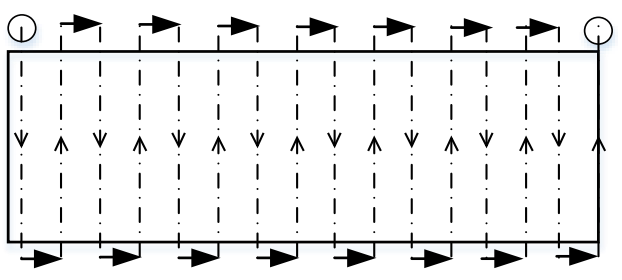

(a)

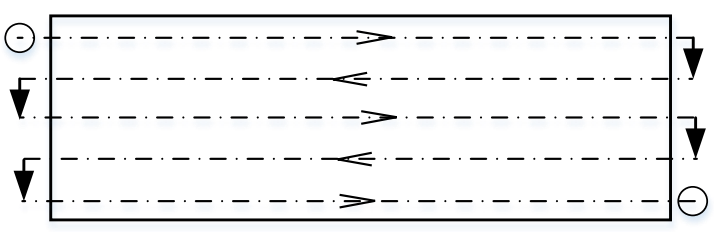

(b)

Fig.3 (a) Toolpath strategies in $\mathrm{Y}$ cutting direction (b) Toolpath strategies in $\mathrm{X}$ cutting direction

In order to better understand the correlation between SEC and MRR (feed rate, width of cut and depth) as well as spindle speed, four factors and three levels are used for roughing machining shown in Table 3. Machining parameters for the experiments in VMC850E is shown in Table 3. The same experiment is carried out in the same machining parameters, while cutting direction is different with $\mathrm{X}$ and $\mathrm{Y}$ cutting direction separately.

Table 3 Machining parameters for the experiments

\begin{tabular}{lllll}
\hline Levels & Spindle speed $(\mathrm{RPM})$ & Feed rate $(\mathrm{mm} / \mathrm{min})$ & Width of cut $(\mathrm{mm})$ & Deepen of cut $(\mathrm{mm})$ \\
\hline Level 1 & 1000 & 100 & 4 & 0.2 \\
Level 2 & 1500 & 150 & 6 & 0.3 \\
Level 3 & 2000 & 200 & 8 & 0.4 \\
\hline
\end{tabular}

\subsection{Experiment results analysis}

The standby power is obtained through 20 times measurement when machine tools is opened with display screen as shown in Table 4 . The average standby power is $342.4 \mathrm{~W}$. The rapid powers axis are measured using G00 node in $\mathrm{X}, \mathrm{Y}$ and $\mathrm{Z}$ individually, as shown in Table 5. Feed power in $\mathrm{X}, \mathrm{Y}, \mathrm{Z}+$, and $\mathrm{Z}$ - direction are shown in Table 6 with 
regression equation.

Table 4 The standby power in 20 times

\begin{tabular}{lllll}
\hline Number & Standby power $(\mathrm{W})$ & Number & Standby power $(\mathrm{W})$ & Average power $(\mathbf{W})$ \\
\hline 1 & 347 & 11 & 343 & \\
2 & 345 & 12 & 341 & \\
3 & 345 & 13 & 339 & \\
4 & 341 & 14 & 342 & \\
5 & 348 & 15 & 338 & \\
6 & 340 & 16 & 344 & \\
7 & 339 & 17 & 343 & \\
8 & 340 & 18 & 342 & $\mathbf{3 4 2 . 4}$ \\
9 & 346 & 19 & 338 & \\
10 & 344 & 20 & 343 & \\
\hline
\end{tabular}

Table 5 The rapid power in $X, Y$ and $Z$ axis

\begin{tabular}{lll}
\hline Axis & Rapid feed rates $(\mathrm{m} / \mathrm{min})$ & Rapid power $(\mathrm{W})$ \\
\hline $\mathrm{X}$ & 24 & 377 \\
$\mathrm{Y}$ & 24 & 389 \\
$\mathrm{Z}$ & 15 & 370 \\
\hline
\end{tabular}

The feed power are measured using G01 node in X,Y, Z+, and Z- directions in three levels feed rate. Using Eq. (5) and the measured data, regression equation could be obtained as shown in Table 6 . The correlation coefficient can reach to more than $97.58 \%$.

Table 6 Feed power in $\mathrm{X}, \mathrm{Y}, \mathrm{Z}+$, and $\mathrm{Z}$ - direction

\begin{tabular}{llll}
\hline Feed rate (mm/min) & Power $(\mathbf{W})$ & Regression equation & Correlation coefficient \\
\hline 100 X direction & 350 & $P_{\text {x-feed }}=327.00+0.22 f$ & $97.58 \%$ \\
150 X direction & 358 & & \\
200 X direction & 372 & & \\
100 Y direction & 357 & $P_{\text {y-feed }}=319.33+0.38 f$ & $99.91 \%$ \\
150 Y direction & 377 & & \\
200 Y direction & 395 & $P_{Z+\text { feed }}=350+0.04 f$ & $100 \%$ \\
100 Z+ direction & 354 & & \\
150 Z+ direction & 356 & & \\
200 Z+ direction & 358 & $P_{Z \text {-feed }}=337+0.08 f$ & \\
100 Z- direction & 345 & & \\
150 Z- direction & 349 & & \\
200 Z- direction & 353 & & \\
\hline
\end{tabular}

The spindle air running power is measured at different speed from 500 RPM to 5100 RPM. Each time keep operating above 5 minutes. The power load is shown in Table 7 with regression equation in different speed square. Overall trend chart is shown in Fig.4. From the chart, we can see that the power is divided into four part form due to load and frictional loss. 
Table 7 Average power load at various spindle rates

\begin{tabular}{|c|c|c|}
\hline Spindle speed (RPM) & Average power $(\mathrm{W})$ & Regression equation \\
\hline 500 & 559 & $P_{\text {spindle }}=453.6+0.2704 \cdot n$ \\
\hline 600 & 617 & $500<n \leq 1500$ \\
\hline 800 & 667 & \\
\hline 900 & 730 & \\
\hline 1100 & 769 & \\
\hline 1200 & 796 & \\
\hline 1400 & 816 & \\
\hline 1500 & 838 & \\
\hline 1700 & 783 & $P_{\text {spindle }}=1459-0.6184 n+0.000129 n^{2}$ \\
\hline 1800 & 761 & $1500<n \leq 2400$ \\
\hline 2000 & 742 & \\
\hline 2100 & 729 & \\
\hline 2300 & 720 & \\
\hline 2400 & 719 & \\
\hline 2600 & 720 & $P_{\text {spindle }}=680.61+0.01493 \cdot n$ \\
\hline 2700 & 721 & $2400<n \leq 3300$ \\
\hline 2900 & 723 & \\
\hline 3000 & 725 & \\
\hline 3200 & 729 & \\
\hline 3300 & 730 & \\
\hline 3500 & 756 & $P_{\text {spindle }}=308.0+0.12963 \cdot n$ \\
\hline 3600 & 762 & $3300<n \leq 5100$ \\
\hline 3800 & 810 & \\
\hline 3900 & 813 & \\
\hline 4100 & 850 & \\
\hline 4200 & 851 & \\
\hline 4500 & 900 & \\
\hline 4800 & 937 & \\
\hline 5100 & 954 & \\
\hline
\end{tabular}

According to the data in the Table 7, it was observed that the spindle exhibits four different characteristics in non-load state, whose zone was divided into A, B, C and D. The relationship between spindle power and speed are fitted using linear or quadratic formula expressed as

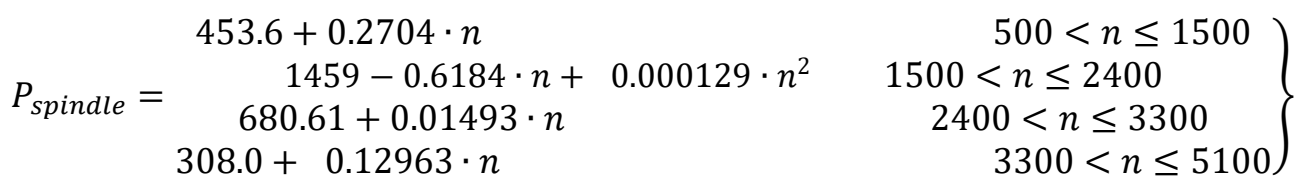

The machined workpiece in $Y$ direction cutting and $X$ direction cutting are shown in Fig.5. Experimental results for milling in $\mathrm{Y}$ direction cutting and $\mathrm{Y}$ direction cutting are shown in Tables 8 and 9. 
Table 8 Experimental results for milling in $\mathrm{Y}$ direction cutting

\begin{tabular}{|c|c|c|c|c|c|c|c|}
\hline Trial & $N(r / m i n)$ & $\mathbf{f}(\mathrm{mm} / \mathrm{min})$ & $a_{p}(m m)$ & $a_{e}(\mathbf{m m})$ & $\operatorname{MRR}\left(\mathrm{mm}^{3} / \mathrm{s}\right)$ & $\operatorname{SEC}\left(\mathrm{J} / \mathrm{mm}^{3}\right)$ & $\mathbf{P}(\mathbf{W})$ \\
\hline 1 & 1000 & 100 & 0.2 & 4 & 1.33 & 593.25 & 791 \\
\hline 2 & 1000 & 100 & 0.3 & 6 & 3 & 270.67 & 812 \\
\hline 3 & 1000 & 100 & 0.4 & 8 & 5.33 & 159.34 & 850 \\
\hline 4 & 1000 & 150 & 0.2 & 4 & 2 & 402 & 804 \\
\hline 5 & 1000 & 150 & 0.3 & 6 & 4.5 & 187.33 & 843 \\
\hline 6 & 1000 & 150 & 0.4 & 8 & 8 & 108 & 864 \\
\hline 7 & 1000 & 200 & 0.2 & 4 & 2.67 & 303 & 808 \\
\hline 8 & 1000 & 200 & 0.3 & 6 & 6 & 143 & 858 \\
\hline 9 & 1000 & 200 & 0.4 & 8 & 10.67 & 81.94 & 874 \\
\hline 10 & 1500 & 100 & 0.2 & 6 & 2 & 429.5 & 859 \\
\hline 11 & 1500 & 100 & 0.3 & 8 & 4 & 221 & 884 \\
\hline 12 & 1500 & 100 & 0.4 & 4 & 2.67 & 325.5 & 868 \\
\hline 13 & 1500 & 150 & 0.2 & 6 & 3 & 291.67 & 875 \\
\hline 14 & 1500 & 150 & 0.3 & 8 & 6 & 151.33 & 908 \\
\hline 15 & 1500 & 150 & 0.4 & 4 & 4 & 220.75 & 883 \\
\hline 16 & 1500 & 200 & 0.2 & 6 & 4 & 221.5 & 886 \\
\hline 17 & 1500 & 200 & 0.3 & 8 & 8 & 114.13 & 913 \\
\hline 18 & 1500 & 200 & 0.4 & 4 & 5.33 & 167.63 & 894 \\
\hline 19 & 2000 & 100 & 0.2 & 8 & 2.67 & 285 & 760 \\
\hline 20 & 2000 & 100 & 0.3 & 4 & 2 & 378 & 756 \\
\hline 21 & 2000 & 100 & 0.4 & 6 & 4 & 191.5 & 766 \\
\hline 22 & 2000 & 150 & 0.2 & 8 & 4 & 191.75 & 767 \\
\hline 23 & 2000 & 150 & 0.3 & 4 & 3 & 254.33 & 763 \\
\hline 24 & 2000 & 150 & 0.4 & 6 & 6 & 130.5 & 783 \\
\hline 25 & 2000 & 200 & 0.2 & 8 & 5.33 & 144.94 & 773 \\
\hline 26 & 2000 & 200 & 0.3 & 4 & 4 & 191.75 & 767 \\
\hline 27 & 2000 & 200 & 0.4 & 6 & 8 & 100.13 & 801 \\
\hline
\end{tabular}

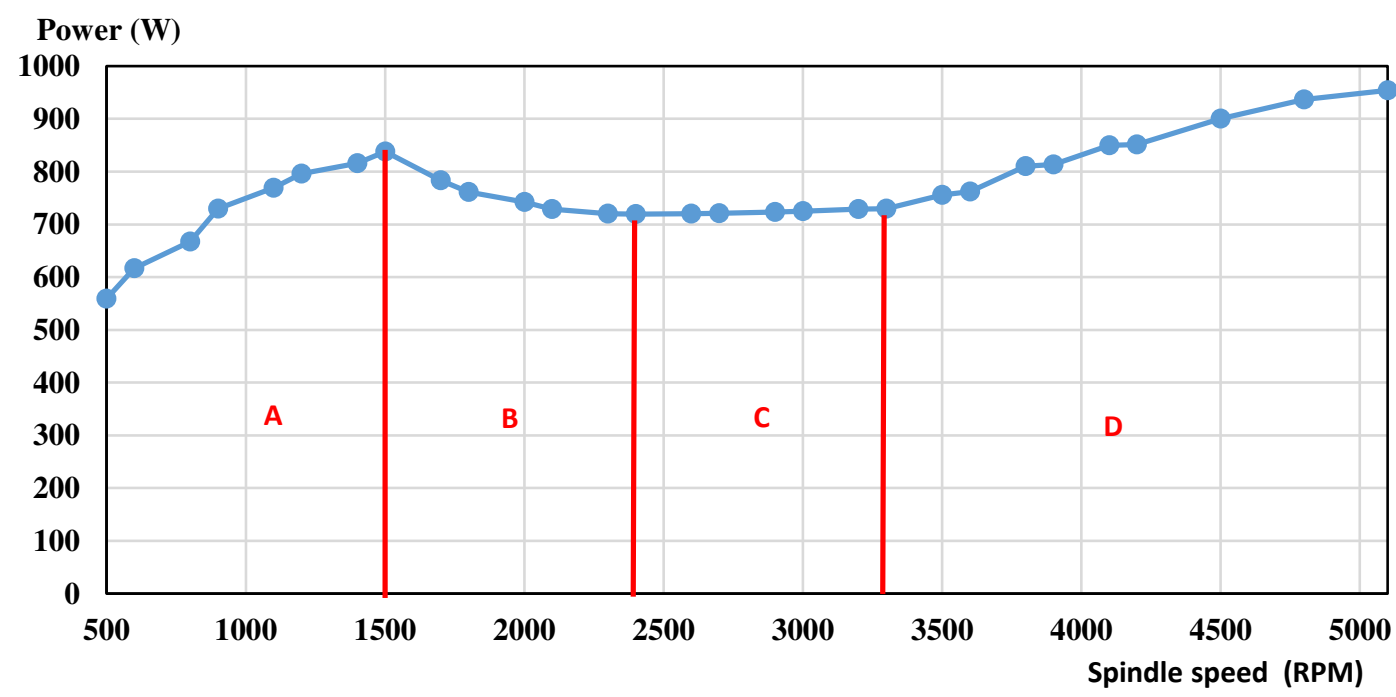

Fig. 4 Average power of spindle at various spindle rates 


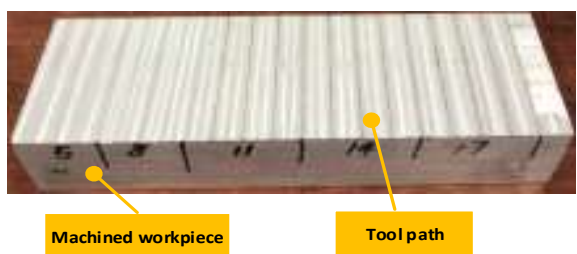

(a)

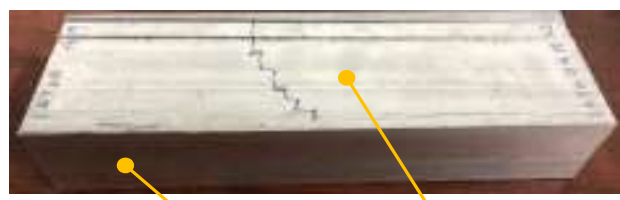

Tool path

(b)

Fig. 5 (a) Toolpath strategies $Y$ direction cutting (b) Toolpath strategies $X$ direction cutting

According to the data of Table 8, the regression equation of $S E C_{y}$ in Y cutting direction is obtained by fragments based on spindle speed. The correlation coefficient in each part could also reach $99.99 \%$, which explains the necessity of segmentation. If it is not segmented, the correlation coefficient of SEC is below $98 \%$, while correlation coefficient of cutting power is just $24 \%$. Similarly, the SEC and power are obtained in X direction cutting as shown in Table 9.

$$
\left.S E C_{y}=\begin{array}{cc}
11.781+0.11771 \cdot \frac{n}{M R R}+\frac{659.65}{M R R} & 0<n \leq 1500 \\
8.548-0.22121 \cdot \frac{n}{M R R}+\frac{1178.3}{M R R} & 1500<n \leq 2000
\end{array}\right\}
$$

Table 9 Experimental results for milling in $\mathrm{X}$ direction cutting

\begin{tabular}{|c|c|c|c|c|c|c|c|}
\hline Trial & $N(r / m i n)$ & $\mathbf{f}(\mathrm{mm} / \mathrm{min})$ & $a_{p}(\mathbf{m m})$ & $\mathrm{ae}_{\mathrm{e}}(\mathrm{mm})$ & $\operatorname{MRR}\left(\mathrm{mm}^{3} / \mathbf{s}\right)$ & $\operatorname{SEC}\left(\mathrm{J} / \mathrm{mm}^{3}\right)$ & $\mathbf{P}(\mathbf{W})$ \\
\hline 1 & 1000 & 100 & 0.2 & 4 & 1.33 & 558 & 744 \\
\hline 2 & 1000 & 100 & 0.3 & 6 & 3 & 252 & 756 \\
\hline 3 & 1000 & 100 & 0.4 & 8 & 5.33 & 143.43 & 765 \\
\hline 4 & 1000 & 150 & 0.2 & 4 & 2 & 376 & 752 \\
\hline 5 & 1000 & 150 & 0.3 & 6 & 4.5 & 168.89 & 760 \\
\hline 6 & 1000 & 150 & 0.4 & 8 & 8 & 96.25 & 770 \\
\hline 7 & 1000 & 200 & 0.2 & 4 & 2.67 & 282.75 & 754 \\
\hline 8 & 1000 & 200 & 0.3 & 6 & 6 & 127.67 & 766 \\
\hline 9 & 1000 & 200 & 0.4 & 8 & 10.67 & 72.94 & 778 \\
\hline 10 & 1500 & 100 & 0.2 & 6 & 2 & 416.5 & 833 \\
\hline 11 & 1500 & 100 & 0.3 & 8 & 4 & 211.25 & 845 \\
\hline 12 & 1500 & 100 & 0.4 & 4 & 2.67 & 313.885 & 837 \\
\hline 13 & 1500 & 150 & 0.2 & 6 & 3 & 283.33 & 850 \\
\hline 14 & 1500 & 150 & 0.3 & 8 & 6 & 142.33 & 854 \\
\hline 15 & 1500 & 150 & 0.4 & 4 & 4 & 210.75 & 843 \\
\hline 16 & 1500 & 200 & 0.2 & 6 & 4 & 211 & 844 \\
\hline 17 & 1500 & 200 & 0.3 & 8 & 8 & 107.25 & 858 \\
\hline 18 & 1500 & 200 & 0.4 & 4 & 5.33 & 159 & 848 \\
\hline 19 & 2000 & 100 & 0.2 & 8 & 2.67 & 273.56 & 729.5 \\
\hline 20 & 2000 & 100 & 0.3 & 4 & 2 & 362.25 & 724.5 \\
\hline 21 & 2000 & 100 & 0.4 & 6 & 4 & 180 & 720 \\
\hline 22 & 2000 & 150 & 0.2 & 8 & 4 & 182.5 & 730 \\
\hline 23 & 2000 & 150 & 0.3 & 4 & 3 & 242.33 & 727 \\
\hline 24 & 2000 & 150 & 0.4 & 6 & 6 & 123.33 & 740 \\
\hline 25 & 2000 & 200 & 0.2 & 8 & 5.33 & 138.08 & 736.4 \\
\hline 26 & 2000 & 200 & 0.3 & 4 & 4 & 182.4 & 729.6 \\
\hline 27 & 2000 & 200 & 0.4 & 6 & 8 & 93.13 & 745 \\
\hline
\end{tabular}


According to the data of Table 9, the regression equation of $S E C_{x}$ in $\mathrm{X}$ cutting direction is obtained by fragments based on spindle speed.

$$
\left.S E C_{x}=\begin{array}{cc}
4.487+0.17312 \cdot \frac{n}{M R R}+\frac{566.9}{M R R} & 0<n \leq 1500 \\
3.698-0.22607 \cdot \frac{n}{M R R}+\frac{1168.21}{M R R} & 1500<n \leq 2000
\end{array}\right\}
$$

\subsection{Discussion}

From the above data, we can see that the cutting specific energy consumption is different in $\mathrm{X}$ and $\mathrm{Y}$ direction. The compare of power in each time machining is shown in Fig.6. We can see that the cutting power of $\mathrm{X}$ direction is lower than $\mathrm{Y}$ direction at the same cutting parameters. The reason is mainly that $\mathrm{Y}$ direction need support the bigger load when $\mathrm{Y}$ axis movement. Therefore, the energy consumption should be calculated individually for improving accuracy of energy prediction. Similarly, the SEC in Y is also bigger than X direction shown in Fig.7.

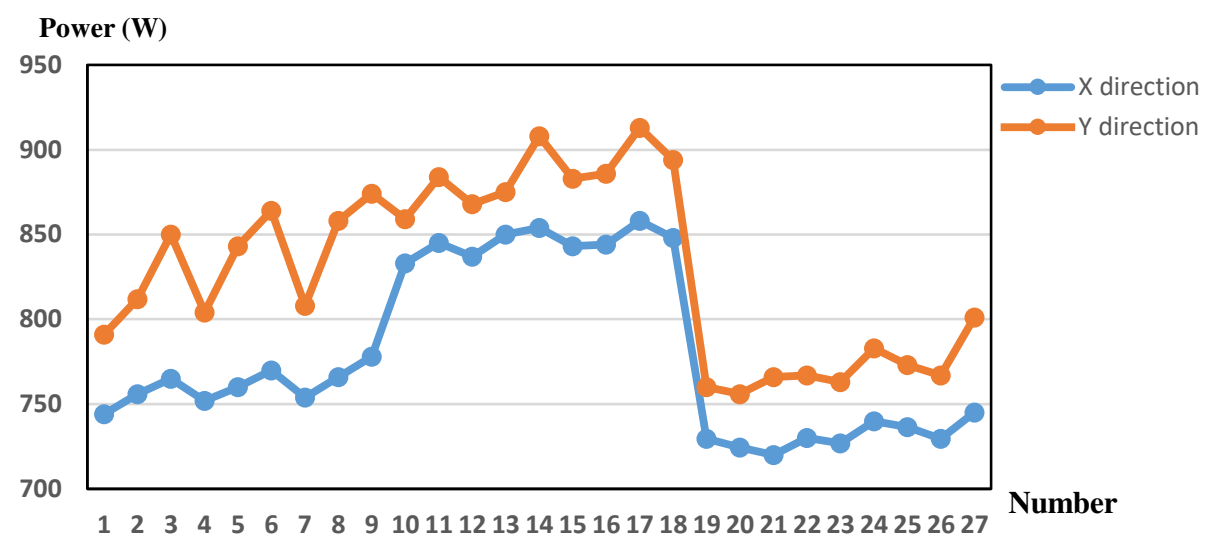

Fig. 6 The power compare of $X$ and $Y$ direction cutting in the same parameters

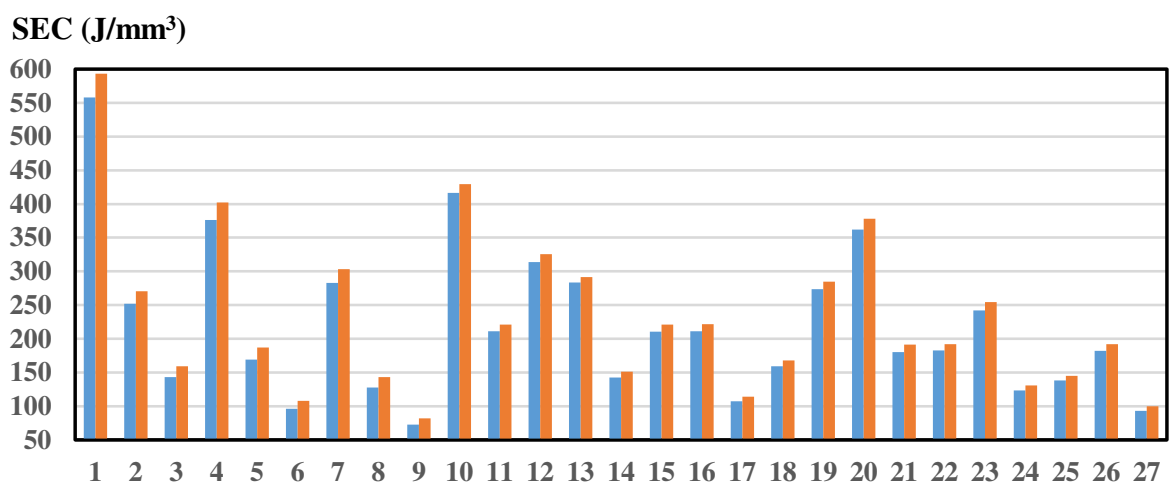

X direction

$\square$ Y direction

Fig. 7 The SEC compare of $X$ and $Y$ direction cutting in the same parameters

For validating the proposed method, the correlation coefficient summary in different model is analyzes in Table 10 , which explains the necessity of segmentation. When the SEC as a whole without segmented, the coefficient Rsquare of models in $\mathrm{Y}$ and $\mathrm{X}$ cutting direction is $98.95 \%$ and $98.41 \%$ separately. Nevertheless, the R-square values could reach $99.98 \%$ and $99.99 \%$ if the $S E C$ model is established based on the spindle speed $n$ space. It is clearly shows that there is a direct correlation between SEC and $n$ and $M R R$. The difference of SEC without segmented and segmented is not particularly obvious due to measurement and data handling error inevitability. Then, we analyze the cutting power whether or not has the same results. However, it emerges an issue for R-square values of relationship between cutting power and $n$ and $M R R$, just having $25.45 \%$ and $36.65 \%$ in $\mathrm{Y}$ and $\mathrm{X}$ direction respectively. In this basis, the regression mathematic model of cutting power will lead to a mistake in following calculation. This result 
is inconsistent with the facts leading to cause puzzle for users and research who will understand they have no relationship.

The source of this issue must be found in order to increase robust of SEC model and cutting power model. Since the MRR is invariable for the same cutting parameters, the issue should be the spindle rotation power under different speed. Hence, we analyzed the R-square value of relationship between spindle power and speed just has $49.18 \%$ without segmented, while the values are exceed $95.27 \%$ with segmented. The above analysis indicate that piecewise representation is necessary for cutting energy prediction model according to the spindle rotation power characteristics in non-load. Therefore, the experiment of spindle rotation power in non-load for specific CNC machine should be carried out to observe the variable characteristics, which not consume too much time. Meanwhile, the total cutting energy calculated by SEC and material removal volumes will reduce the error rate compared with cutting power and cutting time approach.

Table 10 Different model summary results

\begin{tabular}{lll}
\hline Model & $\mathrm{S}$ & R-square \\
\hline SEC without segmented in $\mathrm{Y}$ cutting direction & 12.8025 & $98.95 \%$ \\
SEC in $\mathrm{Y}$ cutting direction $(\mathrm{n}<1500)$ & 1.52747 & $99.99 \%$ \\
SEC in $\mathrm{Y}$ cutting direction $(\mathrm{n}>1500)$ & 0.77535 & $99.99 \%$ \\
SEC without segmented in $\mathrm{X}$ cutting direction & 15.1233 & $98.41 \%$ \\
SEC in $\mathrm{X}$ cutting direction $(\mathrm{n}<1500)$ & 1.22346 & $99.99 \%$ \\
SEC in $\mathrm{X}$ cutting direction $(\mathrm{n}>1500)$ & 1.2659 & $99.98 \%$ \\
Cutting power without segmented in $\mathrm{Y}$ direction & 43.2568 & $36.65 \%$ \\
Cutting power in $\mathrm{Y}$ cutting direction $(\mathrm{n}<1500)$ & 8.04992 & $95.55 \%$ \\
Cutting power in $\mathrm{Y}$ cutting direction $(\mathrm{n}>1500)$ & 4.05947 & $99.61 \%$ \\
Cutting power without segmented in $\mathrm{X}$ direction & 45.099 & $25.45 \%$ \\
Cutting power in $\mathrm{X}$ cutting direction $(\mathrm{n}<1500)$ & 5.90827 & $98.46 \%$ \\
Cutting power in $\mathrm{X}$ cutting direction $(\mathrm{n}>1500)$ & 4.09465 & $99.58 \%$ \\
Spindle power without segmented & 61.775 & $49.18 \%$ \\
Spindle power $(\mathrm{n}<=1500)$ & 23.6075 & $95.27 \%$ \\
Spindle power $(1500<\mathrm{n}<=2400)$ using linear equation & 8.15926 & $91.74 \%$ \\
Spindle power $(1500<\mathrm{n}<=2400)$ using quadratic equation & 2.94637 & $99.19 \%$ \\
Spindle power $(2400<\mathrm{n}<=3300)$ & 0.99932 & $95.58 \%$ \\
Spindle power $(3300<\mathrm{n}<=5100)$ & 10.3088 & $98.16 \%$ \\
\hline
\end{tabular}

From the above analysis, we can obtain the following energy saving strategies:

(1) The selection of machine tools will directly affect the standby energy, which is the basic energy consumption in whole machining process. The different machines have different standby power, and hence, it should be considered as one of energy evaluation indicators.

(2) The mass increase of spindle structure system will lead the power increase in the $Z+$ direction, which need overcome major obstacles. Similarly, the feed powers in $\mathrm{X}$ and $\mathrm{Y}$ directions are also different due to the mass difference. The guide way of $\mathrm{Y}$ axis need support the mass of $\mathrm{X}$ axis leading to the power increasing.

(3) After determining the machine tools, tool path will also affect the total energy consumption due to air cutting distance and time. Therefore, the efforts for reducing distance of air cutting through optimizing tool path and process route planning are coming.

(4) The cutting direction also affect the energy consumption in $\mathrm{X}$ and $\mathrm{Y}$ directions due to the cutting vibration intensity, which increase the cutting force and cutting power studied in literature [22]. 
(5) The cutting parameters (spindle speed, depth of cutting, width of cutting and feed rate) lead to the difference of the material remove rate and specific energy consumption. In the same cutting condition, specific energy consumption represents energy efficiency of cutting process.

\section{Conclusions and future work}

This paper proposed improved energy model for predicting energy consumption of machined part in CNC milling machine. In order to better apply the proposed model in NC nodes of CNC control system, rapid feed and feed power in $\mathrm{X}, \mathrm{Y}$ and $\mathrm{Z}$ axis are considered separately. Furthermore, the relationship of spindle power and speed is deeply analysis through experiment in CNC milling machine, which is not always the linear proportion due to the different of constant torque speed regulation and constant power speed regulation. On that basis, energy model of cutting material is also be improved through segmented form for spindle speed to enhance the accuracy of predicting energy consumption of workpiece. They are not be considered in existing energy models. The contribution of this paper is mainly to make energy consumption prediction of CNC machining process easier to achieve based on $\mathrm{NC}$ nodes of specific a part. Apart from that, the users just need to determine correlation coefficient of their CNC machines' current state without considering and searching other factors or handbook.

From the experiment results, we also could find that it is very necessary to build power models of different moving axes separately. On the same machining parameters, feed power of $Y$ axis movement is higher than $X$ axis. Additionally, cutting power in $\mathrm{Y}$ direction is also higher than $\mathrm{X}$ direction, which leads to SEC in $\mathrm{Y}$ cutting direction more than $\mathrm{X}$ cutting direction. This means $\mathrm{Y}$ cutting direction will consume more energy than $\mathrm{X}$ cutting direction for the same material remove volume. Additionally, the total cutting energy calculated by SEC and material removal volumes will reduce the error rate compared with cutting power and cutting time approach. Therefore, the machining process could be optimized through selecting cutting direction under meeting the requirements of machining surface accuracy.

The $\mathrm{CNC}$ vertical machining center is used as a research object with $\mathrm{X}, \mathrm{Y}$ and $\mathrm{Z}$ axis. In future, more kinds of machine tools should be studied for expanding the use of energy consumption models. Additionally, intelligent methods such as deep learning and digital Twin technology will be integrated into energy prediction software to accelerate the development of sustainable manufacturing in industry.

\section{Funding}

This research is funded by the National Natural Science Foundation of China Grant No. 51605294. Shi Huang, Guozhen Bai, Yilong Wu and Haohao Guo are thanked for providing technical support during the experiments.

\section{Authors' contributions}

Chunhua Feng: Conceptualization, Methodology, Software, Validation, Writing-Original Draft, Funding acquisition. Xiang Chen: Investigation, Data Curation, Software. Jingyang Zhang: Investigation, Data Curation, Resources. Yugui Huang: Investigation, Data Curation, Resources.

\section{Data availability: All the data have been presented in the manuscript.}

\section{Declarations}

The authors declare that they have no known competing financial interests or personal relationships that could have appeared to influence the work reported in this paper.

Ethical approval: Not applicable.

Consent to participate: The authors declare that they all consent to participate this research. 
Consent to publish: The authors declare that they all consent to publish the manuscript.

\section{References}

[1] Zhou L, Li J, Li F, Meng Q, Li J, Xu X. Energy consumption model and energy efficiency of machine tools: a comprehensive literature review. Journal of Cleaner Production 2016; 112: 3721-3734.

[2] Zhao G.Y, Liu Z.Y, He Y, Cao, H J, Guo Y.B. Energy consumption in machining: classification, prediction, and reduction strategy. Energy 2017; 133: 142-157.

[3] Gutowski T, Dahmus J, Thiriez A. Electrical energy requirements for manufacturing processes. In 13th CIRP international conference on life cycle engineering 2006, Leuven, Belgium, volume 5, pp. 560-564.

[4] Diaz N, Redelsheimer E, Dornfeld D. Energy consumption characterization and reduction strategies for milling machine tool use. In Hesselbach, J., Herrmann, C. (Eds.), Glocalized Solutions for Sustainability in Manufacturing 2011. Springer Berlin Heidelberg, pp. 263-267.

[5] Kara S, Li W. Unit process energy consumption models for material removal processes. CIRP AnnalsManufacturing Technology 2011; 60(1): 37-40.

[6] Li L, Yan J, Xing Z. Energy requirements evaluation of milling machines based on thermal equilibrium and empirical modeling. Journal of Cleaner Production 2013; 52: 113-121.

[7] Newman S.T, Nassehi A, Imani-Asrai R, Dhokia V. Energy efficient process planning for CNC machining. CIRP Journal of Manufacturing Science and Technology 2012; 5(2):127 -136.

[8] Balogun V.A, Mativenga P.T. Modelling of direct energy requirements in mechanical machining processes. Journal of Cleaner Production 2013; 41(0): 179 - 186.

[9] Mori M, Fujishima M, Inamasu Y, Oda Y. A study on energy efficiency improvement for machine tools. CIRP Annals - Manufacturing Technology 2011; 60(1):145 - 148.

[10] Balogun V.A, Aramcharoen A, Mativenga P.T, Chuan S.K. Impact of machine tools on the direct energy and associated carbon emissions for a standardized NC toolpath. In Andrew, Y.C., Nee, B.S., Ong, S.K. (Eds.), Reengineering Manufacturing for Sustainability, Springer Singapore 2013, pp. 197-202.

[11] He Y, Liu F, Wu T, Zhong F.P, Peng B. Analysis and estimation of energy consumption for numerical control machining. Proceedings of the Institution of Mechanical Engineers, Part B: Journal of Engineering Manufacture 2012; 226(2):255-266.

[12] Behrendt T, André Zein, Min S. Development of an energy consumption monitoring procedure for machine tools. CIRP Annals - Manufacturing Technology 2012; 61(1): 43-46.

[13] Altnta R.S, Kahya M, zgür H.ü. Modelling and optimization of energy consumption for feature based milling. International Journal of Advanced Manufacturing Technology 2016; 86: 3345-3363.

[14] Moradnazhad M, Unver H.O. Energy consumption characteristics of turn-mill machining. International Journal of Advanced Manufacturing Technology 2017; 91:1991-2016.

[15] Hu L, Tang R, Cai W, Feng Y, Ma X. Optimisation of cutting parameters for improving energy efficiency in machining process. Robotics and Computer Integrated Manufacturing 2019; 59: 406-416.

[16] Shin S.J, Woo J, Rachuri S. Energy efficiency of milling machining: component modeling and online optimization of cutting parameters. Journal of Cleaner Production 2017; 161, 12-29.

[17] Chen X, Li C, Tang Y, Xiao Q. An internet of things based energy efficiency monitoring and management system for machining workshop. Journal of Cleaner Production 2018; 199: 957-968.

[18] He Y, Wu P, Li Y, Wang Y, Wang Y. A generic energy prediction model of machine tools using deep learning algorithms. Applied Energy 2020; 275: 115402.

[19] Xu L, Huang C, Li C, Wang J, Liu H, Wang X. A novel intelligent reasoning system to estimate energy consumption and optimize cutting parameters toward sustainable machining. Journal of Cleaner Production 2020; 
261: 121160.

[20] Edem I.F, Balogun V.A, Nkanang B.D, Mativenga P.T. Software analyses of optimum toolpath strategies from computer numerical control (CNC) codes. International Journal of Advanced Manufacturing Technology 2019; 103: 997-1007.

[21] Moreira L.C, Li W.D, Lu X, Fitzpatrick M.E. Sustainable Machining Process: Qualitative Analysis and Energy Efficiency Optimization. In Li, W., Wang, S., (EDS.), Sustainable Manufacturing and Remanufacturing Management 2019. Coventry, UK. pp. 165-189.

[22] Akkuş H., Yaka H. Experimental and statistical investigation of the effect of cutting parameters on surface roughness, vibration and energy consumption in machining of titanium 6Al-4V ELI (grade 5) alloy. Measurement 167 (2021) 108465. 


\section{Figures}

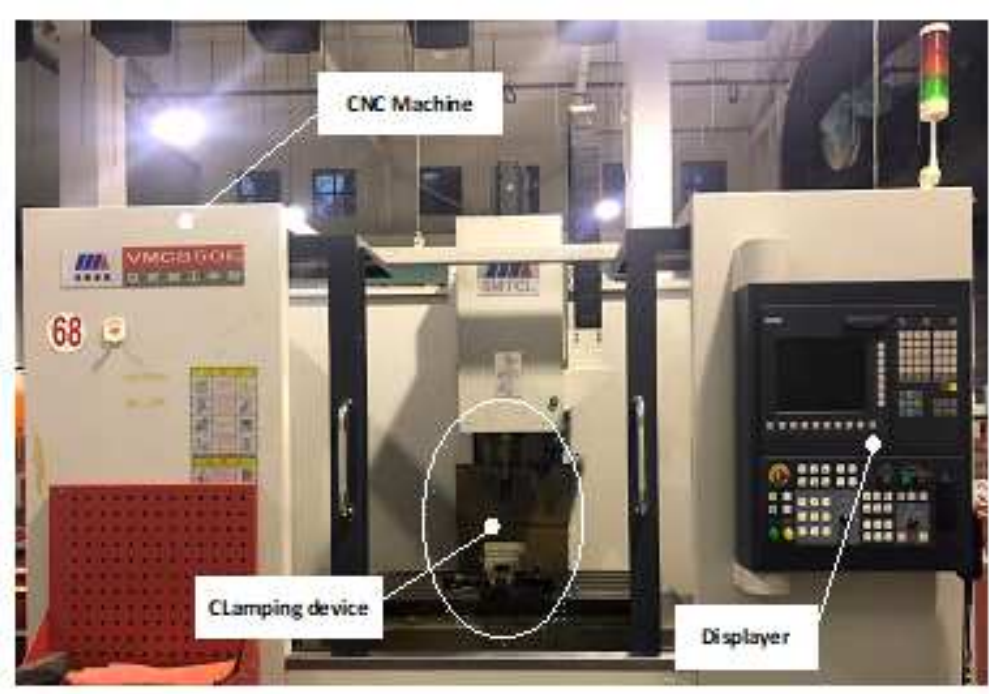

(a)

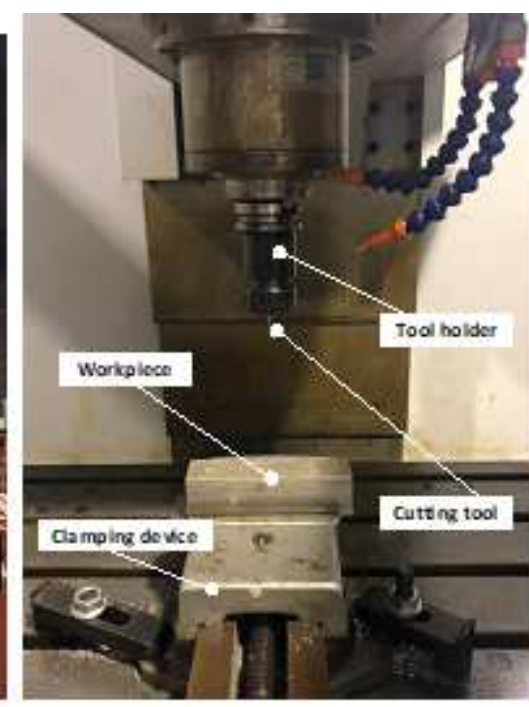

(b)

Figure 1

(a) VMC850E machine (b) Machined workpiece and cutting tool

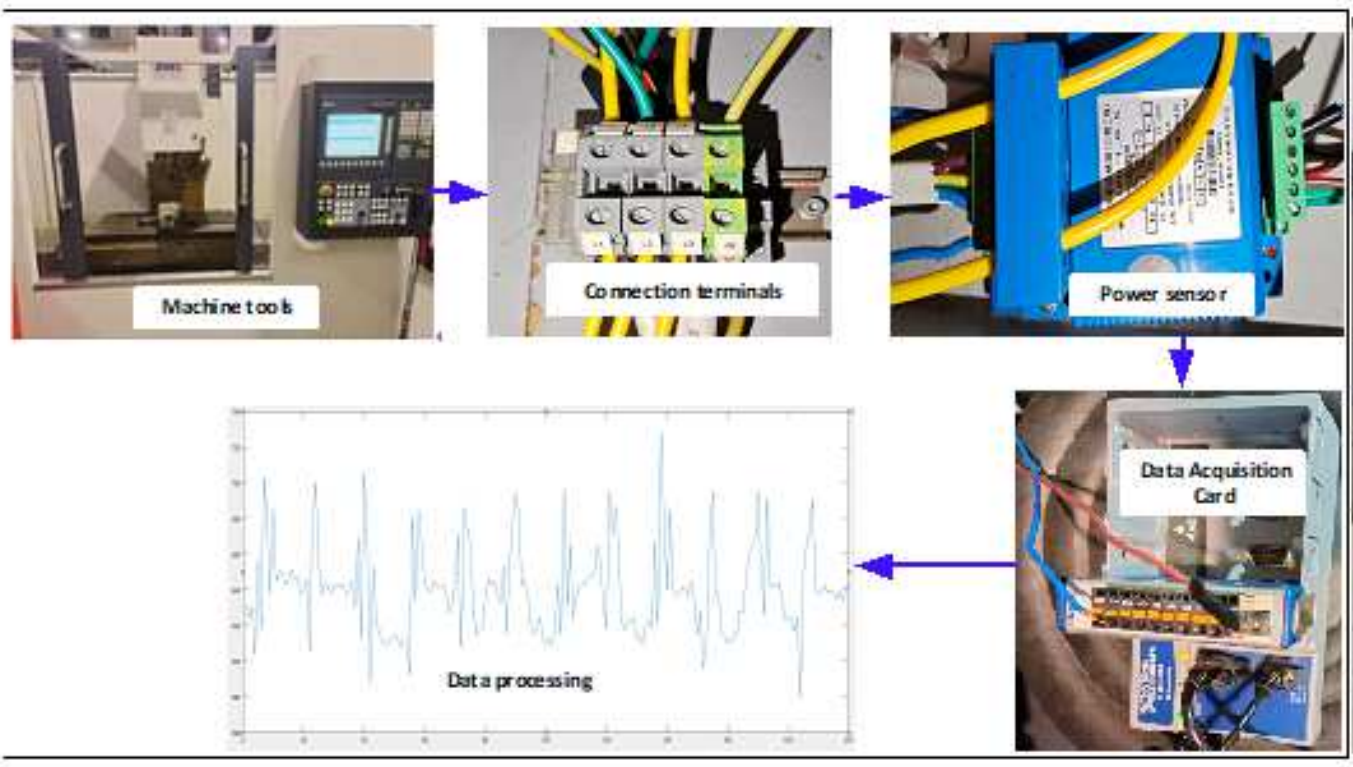

(a)

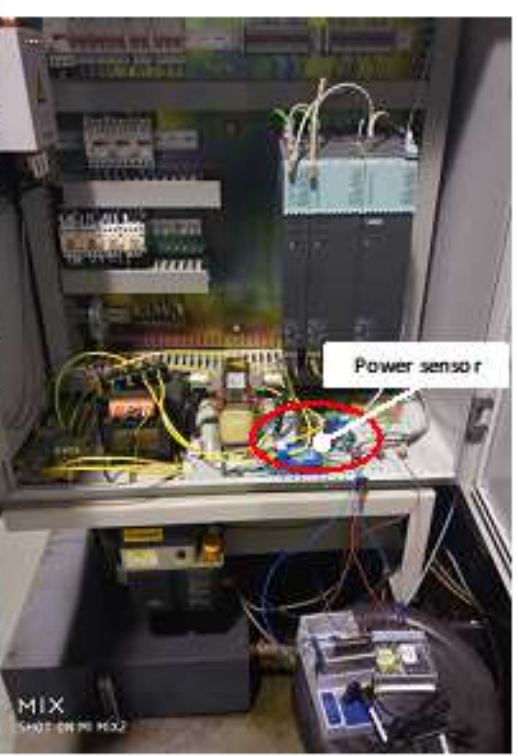

(b)

Figure 2

(a) A diagram for the power data acquisition (b) Connection diagram 


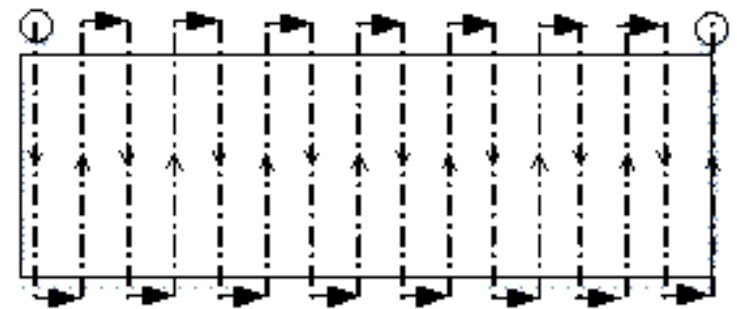

(a)

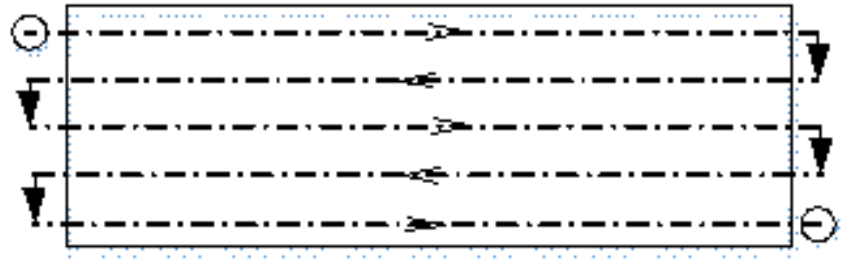

(b)

Figure 3

(a) Toolpath strategies in $\mathrm{Y}$ cutting direction (b) Toolpath strategies in $\mathrm{X}$ cutting direction

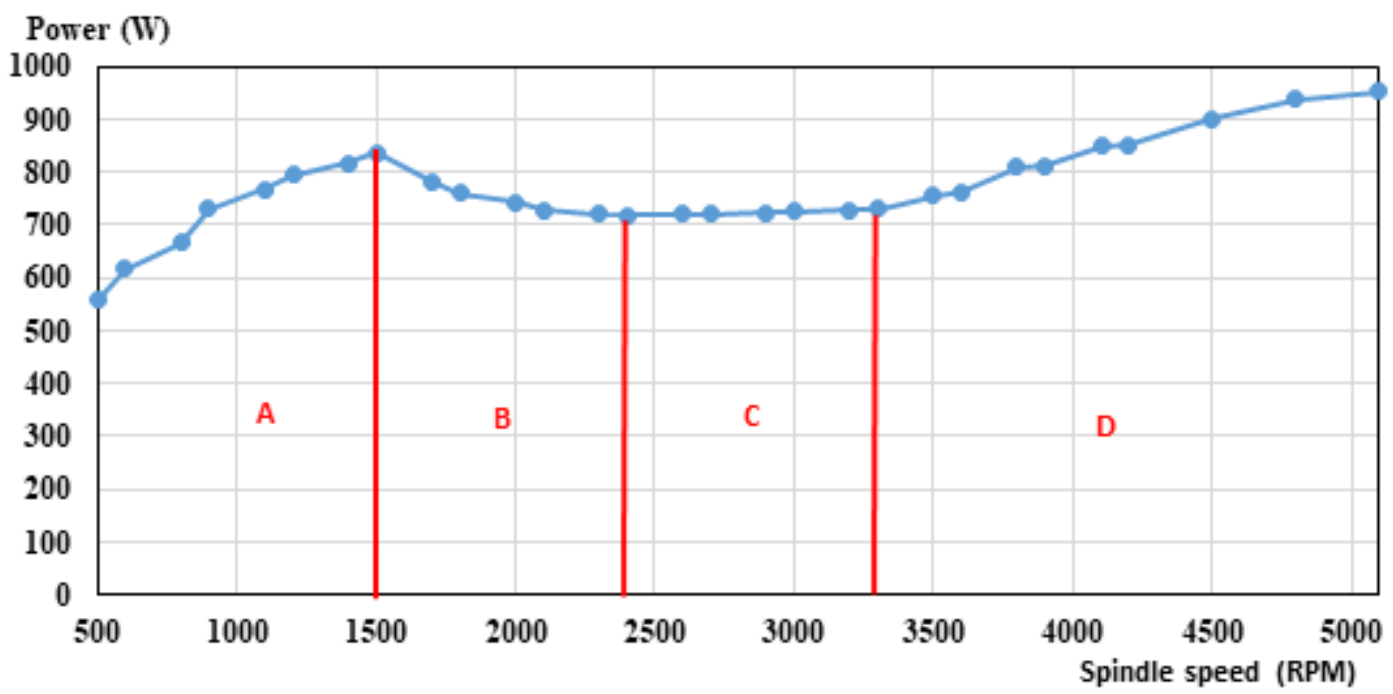

Figure 4

Average power of spindle at various spindle rates

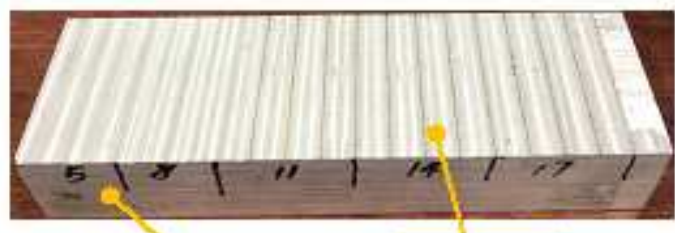

Machined workpiece
Toolpath

(a)

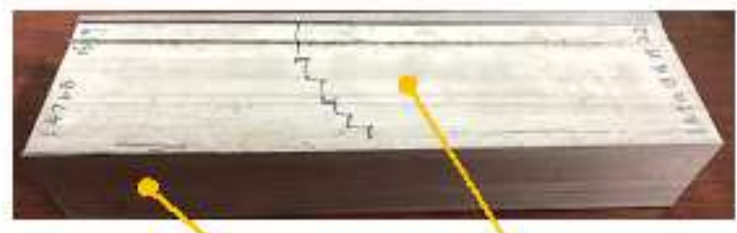

Machined workplece

Toolpath

(b)

Figure 5

(a) Toolpath strategies $Y$ direction cutting (b) Toolpath strategies $X$ direction cutting 


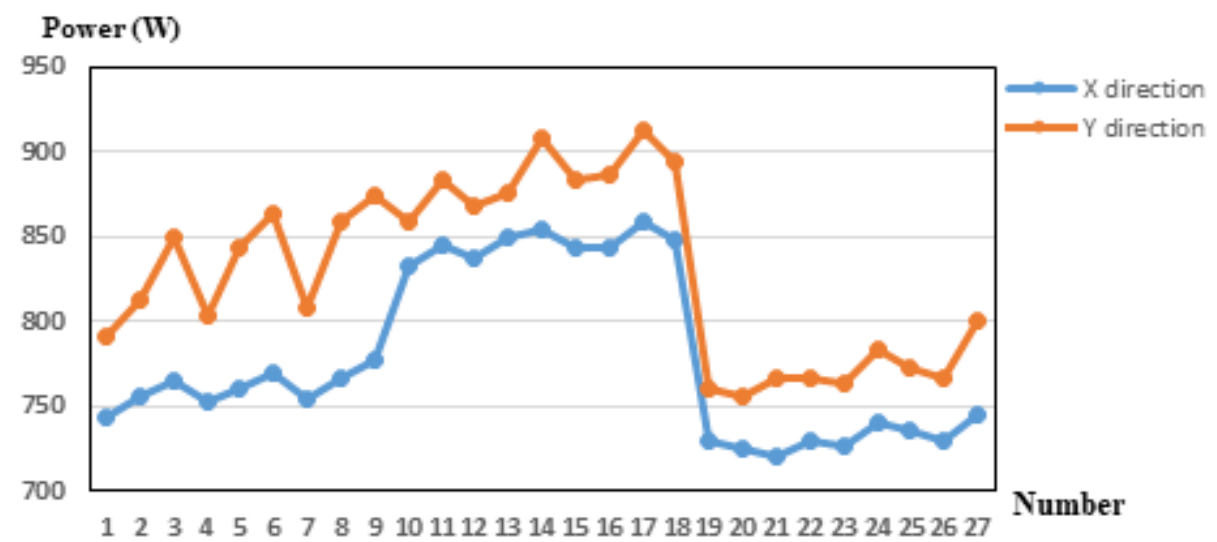

Figure 6

The power compare of $\mathrm{X}$ and $\mathrm{Y}$ direction cutting in the same parameters

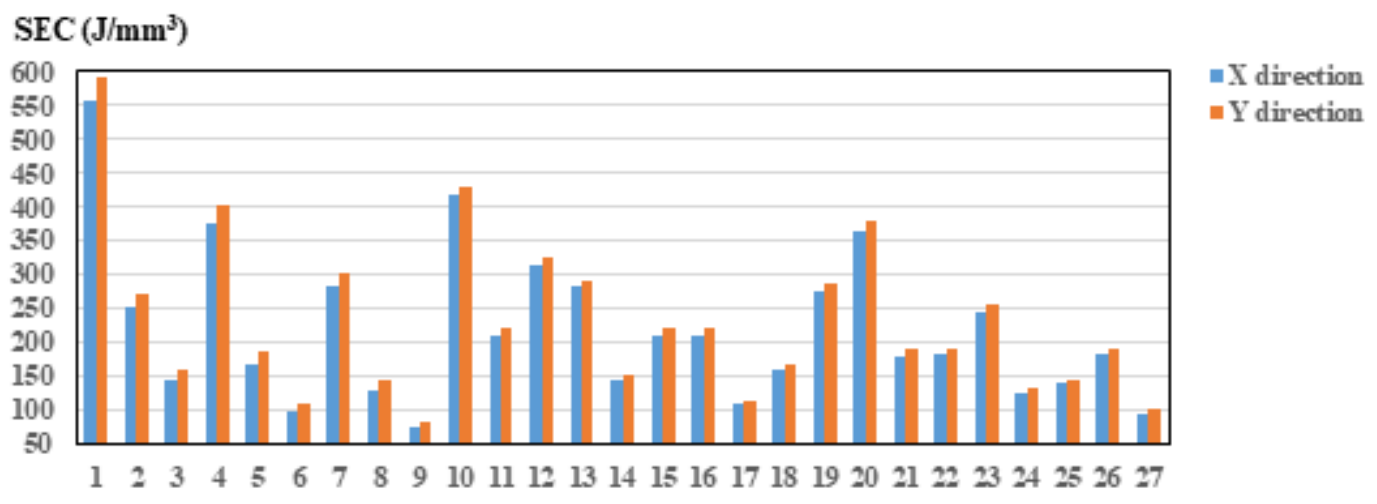

Figure 7

The SEC compare of $X$ and $Y$ direction cutting in the same parameters 